\title{
Optimization of a New Methodology for Determination of Total Phenolic Content in Rice Employing Fast Blue BB and QUENCHER Procedure
}

\author{
Sylvio V. Palombini, Thiago Claus, Swami A. Maruyama, Fabiana Carbonera, Paula F. \\ Montanher, Jesuí V. Visentainer, Sandra T. M. Gomes and Makoto Matsushita*
}

Departamento de Química, Universidade Estadual de Maringá, 87020-900 Maringá-PR, Brazil

\begin{abstract}
Response surface methodology was used to optimize the total phenolic content (TPC) result in white rice, using a new methodology that employed Fast Blue BB (FBBB) reagent, which reacts more specifically with phenolic compounds, along with direct QUENCHER procedure. This is the first time in which such conciliation between FBBB reagent and QUENCHER was done. The obtained model allowed to evaluate how the factors influenced the method linearity $\left(\mathrm{R}^{2}\right)$, improving the choice of the optimal system condition. Furthermore, the similarity between experimental results and values generated by the model indicated the method validity within the studied region. Thus, the optimal condition determined in the present work was 30 min reaction time, $0.17 \mathrm{~mL}$ FBBB reagent and use of $5 \% \mathrm{NaOH}$ as the catalyst for the reaction. This optimized condition suggested that the combination of the method, which used FBBB reagent and the direct QUENCHER procedure, was rapid and effective, yielding high TPC values (1488.73 mg of gallic acid equivalent per $100 \mathrm{~g}$ ).
\end{abstract}

Keywords: Fast Blue BB, QUENCHER procedure, RSM, rice

\section{Introduction}

Nowadays, there is great interest in the study of compounds which show antioxidant capacity ${ }^{1-3}$ due to the knowledge of the harmful effects caused by oxidative stress, such as DNA damage, resulting in carcinogenic effects. ${ }^{4}$ These studies include the determination of the antioxidant capacity of such compounds and also the detection of their total amounts.

Phenolic compounds present in nearly all foods are among compounds that exhibit antioxidant activity. The Folin-Ciocalteu (F-C) method has been used to measure total phenolic content in food. ${ }^{5}$ The F-C assay is a colorimetric method based on the electron transfer reactions between the F-C reagent and phenolic compounds. For a long time, many efforts have been made to improve the assay selectivity. ${ }^{6,7}$ However, this method is not specific and other compounds present in foods, such as sugars, aromatic amines, organic acids and, in particular, ascorbic acid, ${ }^{8}$ can cause interference.

Recently, Medina ${ }^{9}$ proposed a new method that was not affected by these interfering compounds. This new method uses Fast Blue BB diazonium salt (FBBB) reagent, where

*e-mail: mmakoto@uem.br the diazonium group specifically couples with reactive phenolic hydroxyl groups under alkaline conditions to form stable azo complexes, ${ }^{10}$ providing more reliable results compared to the F-C assay.

In addition to this new methodology for total phenolic content (TPC) determination, Serpen et al. ${ }^{11}$ developed a new direct procedure called QUENCHER. This procedure overcomes problems related to losses inherent to commonly applied processes, which employ solvent extraction and/or hydrolysis, used to analyze the antioxidant capacity of foods. Both processes lead to underestimation of the experimental results, as not all molecules responsible for antioxidant activity (phenolic compounds or not) can be efficiently extracted or hydrolyzed. ${ }^{12}$ The QUENCHER procedure avoids these solvent extraction or hydrolysis steps and the reagents act directly on the sample, yielding more accurate results, which take into account the effects that occur between antioxidant compounds in the food matrix, such as synergism. Furthermore, the reagents act on the soluble and insoluble portions of the sample, which is not the case when extraction and/or hydrolysis steps are applied. ${ }^{12}$

The investigation and optimization of the different assays is essential to reach an accurate analysis. Response surface methodology (RSM) is an effective tool for this process. It is a powerful method to evaluate all the effects 
of different factors and their interaction on all response variables. This tool can be used to find a combination of factor levels that produce an optimum response. ${ }^{13}$ Among the different types of designs, one of the most employed is the central composite design (CCD). This experimental design allows to evaluate each independent variable in five different levels, including low ( -1$)$, intermediate (0), high $(+1)$; and the axial levels $(-\alpha$ and $+\alpha)$, making possible the expansion of the region which will be studied. ${ }^{14}$

The QUENCHER procedure, as well the assay proposed by Medina ${ }^{9}$ have been applied to different samples, including rice (Oryza sativa L.), an important crop in Africa, Latin America and Middle East, and the second largest crop produced worldwide, a staple food in many countries, especially in developing countries. ${ }^{15,16}$ However, they have not been combined into a single assay for TPC determination. Therefore, this work aimed to combine the QUENCHER procedure with the new methodology for TPC determination using FBBB reagent and RSM to optimize the TPC analysis in white rice samples.

\section{Experimental}

\section{Materials}

The white rice samples (Oryza sativa L.) were obtained in the local commerce from the city of Maringá (PR, Brazil). All the samples were milled and passed through a 80 mesh $(0.177 \mathrm{~mm})$ sieve, to avoid any influence of different particle sizes in the following experiments. The Fast Blue BB [4-benzoylamino-2,5-dimethoxybenzenediazonium chloride hemi-(zinc chloride)] and gallic acid reagents were obtained from Sigma-Aldrich (St. Louis, MO, USA). The assays were performed employing $\mathrm{NaOH}$ and $\mathrm{Na}_{2} \mathrm{CO}_{3}$ with analytical degree.

\section{Experimental design}

The influence of independent variables in function of TPC results was evaluated through central composite design (CCD, Table 1), applied to RSM. The design used in this work was composed by five levels and three variables, totalizing 22 experiments, presenting 8 factorial points, 8 axial points and 6 central points. The selected variables and intervals were determined based on previous studies found in the literature. ${ }^{9,17}$

\section{Total phenolic content determination}

The TPC determination was carried out according to Medina ${ }^{9}$ applying QUENCHER procedure. ${ }^{11}$ Ten milligrams of previously milled sample was weighed in centrifuge tubes, with subsequent addition of FBBB reagent $(0.1 \%$ in distilled water, $\mathrm{m} / \mathrm{v}$ ) in volumes delimited by design, followed by addition of $0.1 \mathrm{~mL}$ of specific catalyst of each experiment $\left(5 \% \mathrm{NaOH}, \mathrm{m} / \mathrm{v}\right.$ or $20 \% \mathrm{Na}_{2} \mathrm{CO}_{3}, \mathrm{~m} / \mathrm{v}$; all prepared with distilled water) and $9 \mathrm{~mL}$ of water. After reaction times determined for each experiment, the tubes were centrifuged at $9,200 \times \mathrm{g}$ for $4 \mathrm{~min}$. The absorbance of the supernatants was measured at $420 \mathrm{~nm}$ in a Genesys 10 UV-Vis spectrophotometer (Thermo Fisher Scientific, Waltham, MA, USA). Furthermore, for each experiment of design, a control constituted only of the sample with $9 \mathrm{~mL}$ of water was also prepared, with the aim of measuring the natural non-phenolic interfering compounds in the medium.

For each experimental point, a calibration curve was prepared with gallic acid solution in concentrations of 10 , $25,50,100,250$ and $500 \mathrm{mg} \mathrm{L}^{-1}$, adding initially $1 \mathrm{~mL}$ of acid and following the same conditions of time and FBBB volume determined for each experiment, as well as the order of addition of them, that should not be changed. The final results of each assay were derived from calibration curves, expressed in gallic acid equivalent (GAE), by subtracting the obtained values from calibration curves and the blank values of each experiment, giving values in $\mathrm{mg} \mathrm{L}^{-1}$. These values were further multiplied by a conversion factor, taking into account the weighed mass of samples, to obtain the final result on mg GAE $100 \mathrm{~g}^{-1}$.

\section{Statistical analysis}

The experimental results were analyzed through

Table 1. Range and levels of variables used in the central composite design

\begin{tabular}{|c|c|c|c|c|c|}
\hline & \multicolumn{5}{|c|}{ Numerical factor } \\
\hline & -1.4241 & -1 & 0 & +1 & +1.4241 \\
\hline $\mathrm{X}_{1}$ (time / min) & 8.79 & 15.00 & 30.00 & 45.00 & 51.21 \\
\hline \multirow[t]{2}{*}{$\mathrm{X}_{2}\left(\mathrm{FBBB}^{\mathrm{a}} / \mathrm{mL}\right)$} & 0.03 & 0.05 & 0.10 & 0.15 & 0.17 \\
\hline & \multicolumn{5}{|c|}{ Categorical factor } \\
\hline $\mathrm{X}_{3}$ (catalyst $\left.^{\mathrm{b}}\right)$ & \multicolumn{2}{|c|}{$5 \% \mathrm{NaOH}$} & \multicolumn{3}{|c|}{$20 \% \mathrm{Na}_{2} \mathrm{CO}_{3}$} \\
\hline
\end{tabular}

${ }^{\mathrm{a} F a s t}$ Blue BB reagent 0.1\% (m/v); ${ }^{\mathrm{b}} \mathrm{NaOH} 5 \%(\mathrm{~m} / \mathrm{v}), \mathrm{Na}_{2} \mathrm{CO}_{3} 20 \%(\mathrm{~m} / \mathrm{v})$. 
of response surface methodology generated by the Design Expert software, version 7.1. ${ }^{18}$ Model fit quality was evaluated by analysis of variance (ANOVA) and determination coefficients. The general model equation used to fit the data was (equation 1):

$Y=\beta_{0}+\beta_{1} X_{1}+\beta_{2} X_{2}+\beta_{3} X_{3}+\beta_{12} X_{1} X_{2}+\beta_{13} X_{1} X_{3}+$ $\beta_{23} X_{2} X_{3}+\beta_{11} X_{1}^{2}+\beta_{22} X_{2}^{2}+\beta_{33} X_{3}^{2}$

where $\mathrm{Y}$ is the desired response (TPC); $\mathrm{X}_{1}, \mathrm{X}_{2}$ and $\mathrm{X}_{3}$ are independent variables representing time, FBBB volume and catalyst ( $5 \% \mathrm{NaOH}$ and $20 \% \mathrm{Na}_{2} \mathrm{CO}_{3}$ ), respectively; $\beta_{0}$ is the intercept; $\beta_{1}, \beta_{2}$ and $\beta_{3}$ are first order coefficients of the model; $\beta_{12}, \beta_{13}$ and $\beta_{23}$ are linear coefficients for interactions between factors; and $\beta_{11}, \beta_{22}$ and $\beta_{33}$ are quadratic coefficients of the model.

\section{Results and Discussion}

\section{Regression model development}

The first step for the optimization process of the assay is the choice of an experimental design. As described before, the chosen design for this study was CCD. It is noteworthy to mention that the experimental design used in this work differs from central composite rotary design (CCRD), widely used in optimization works ${ }^{19,20}$ in function of the values of the axial points, that in the CCRD are -2 and +2 . This may be risky to an experimental design, since experimental points very distant from the center point may decrease the investigation quality of RSM obtained. ${ }^{14}$ To overcome this possible detrimental factor, intermediate values for the axial points were chosen (Table 1).

The results of statistical analysis applied to experiments generated by CCD are shown in Table 2 .

The responses of the experiments were submitted to analysis of variance, following a model that possesses high significance. Among available models, such as linear, two factor interactions (2FI), polynomial, quadratic and cubic, the quadratic model was selected. In this work, one of the variables was categorical. Thus, two equations in terms of actual values were obtained, one for each categorical variable (catalyst, Table 2). Positive signals in the equations (Table 2) indicated synergic effects, while negative signals indicate antagonistic effects.

Table 2. Analysis of variance (ANOVA), quadratic models and model parameters for the obtained response

\begin{tabular}{lccccc}
\hline Source & Sum of squares & Degrees of freedom & Mean square & F-value & $p$-value \\
\hline Model & $1.967 \times 10^{6}$ & 8 & $2.459 \times 10^{5}$ & 34.84 & $<0.0001$ \\
$\mathrm{X}_{1}{ }^{\mathrm{a}}$ & $3.254 \times 10^{5}$ & 1 & $3.254 \times 10^{5}$ & 46.11 & $<0.0001$ \\
$\mathrm{X}_{2}^{\mathrm{b}}$ & $1.445 \times 10^{6}$ & 1 & $1.445 \times 10^{6}$ & 204.76 & 17.68 \\
$\mathrm{X}_{3}^{\mathrm{c}}$ & $1.248 \times 10^{5}$ & 1 & $1.248 \times 10^{5}$ & 0.052 & 0.0010 \\
$\mathrm{X}_{1} \mathrm{X}_{2}$ & 366.89 & 1 & 366.89 & 0.92 & 0.8232 \\
$\mathrm{X}_{1} \mathrm{X}_{3}$ & 6463.02 & 1 & 6463.02 & 4.76 & 0.3561 \\
$\mathrm{X}_{2} \mathrm{X}_{3}$ & 33610.52 & 1 & 33610.52 & 2.10 & 0.0480 \\
$\mathrm{X}_{1}{ }^{2}$ & 14855.14 & 1 & 14855.14 & 1.10 & 0.1705 \\
$\mathrm{X}_{2}{ }^{2}$ & 7782.47 & 1 & 7782.47 & - & 0.3128 \\
Residual & 91751.13 & 13 & 7057.78 & 3.32 & - \\
Lack of fit & 80930.31 & 9 & 8992.26 & - & - \\
Pure error & 10820.82 & 4 & 2705.21 & - & - \\
Total & $2.059 \times 10^{6}$ & 21 & Model and response & & - \\
\hline
\end{tabular}

Catalyst $5 \% \mathrm{NaOH}$

$\mathrm{TPC}=-85.35481+18.74158 \mathrm{X}_{1}+5098.16739 \mathrm{X}_{2}-9.02950 \mathrm{X}_{1} \mathrm{X}_{2}-0.16119 \mathrm{X}_{1}^{2}+1.05001 \times 10^{4} \mathrm{X}_{2}^{2}$

Catalyst $20 \% \mathrm{Na}_{2} \mathrm{CO}_{3}$

\begin{tabular}{lcccc}
\multicolumn{5}{c}{$\mathrm{TPC}=+168.18962+21.42134 \mathrm{X}_{1}+3264.85021 \mathrm{X}_{2}-9.02950 \mathrm{X}_{1} \mathrm{X}_{2}-0.16119 \mathrm{X}_{1}{ }^{2}+1.05001 \times 10^{4} \mathrm{X}_{2}{ }^{2}$} \\
\hline Mean & Standard deviation & $\mathrm{R}^{2}$ & Adjusted $\mathrm{R}^{2}$ & Coefficient of variation \\
\hline 987.57 & 84.01 & 0.9554 & 0.9280 & 8.51 \\
\hline
\end{tabular}

${ }^{\mathrm{a}}$ time; ${ }^{\mathrm{b}}$ Fast Blue BB reagent; ${ }^{\mathrm{c}}$ catalyst. 
The coefficient of determination value $\left(\mathrm{R}^{2}\right)$ measures the amount of variation in the average explained by the model, and for a well-adjusted model, this value should never be less than 0.80 . When $\mathrm{R}^{2}$ is close to 1 , this indicates the empirical model is suitable for the data, ${ }^{14}$ and the value of 0.9554 indicated a well-adjusted/suitable model for the data (Table 2). However, the addition of variables into the model will always increase the $\mathrm{R}^{2}$ values, independently of its statistical significance. Therefore, a high $\mathrm{R}^{2}$ does not indicate (in every case) the model to which it corresponds is suitable, and the better value would be the adjusted $R^{2}$ $\left(\operatorname{adj}-\mathrm{R}^{2}\right)$ value, that only accounts for significant model variables. ${ }^{14}$ Adj- $\mathrm{R}^{2}$ values higher than 0.90 indicate the model is well-fitted to the data and in the present work the adj- $\mathrm{R}^{2}$ was higher than 0.90 , showing a well-adjusted model. The F-value of the model (34.84), with a $p$-value $<0.0001$, indicates the model is significant at a $95 \%$ trust level. This $p$-value is an important tool to predict if a factor or interaction of factors will be statistically significant, since $p$-values $<0.05$ indicate significance in the proposed model. The $p$-values indicated the $\mathrm{X}_{1}, \mathrm{X}_{2}$ and $\mathrm{X}_{3}$ factors (time, FBBB reagent volume and type of catalyst, respectively) were significant, as well as the $\mathrm{X}_{2}-\mathrm{X}_{3}$ interaction (FBBB reagent volume and type of catalyst, respectively). Other factors, as well as interactions that were not statistically significant, were not removed, as they had no negative effect on the model.

The low coefficient of variation $(\mathrm{CV})$ value (Table 2) indicates the high precision of experimental results. The high $p$-value seen for lack of fit (0.1298) indicated it was not significant term for the model, confirming a well-adjusted model that explains very well the results for the experimental interval.

Another way of evaluate the efficiency of the model fit is the comparison between predicted model values and experimental values (Figure 1). The more similar the values

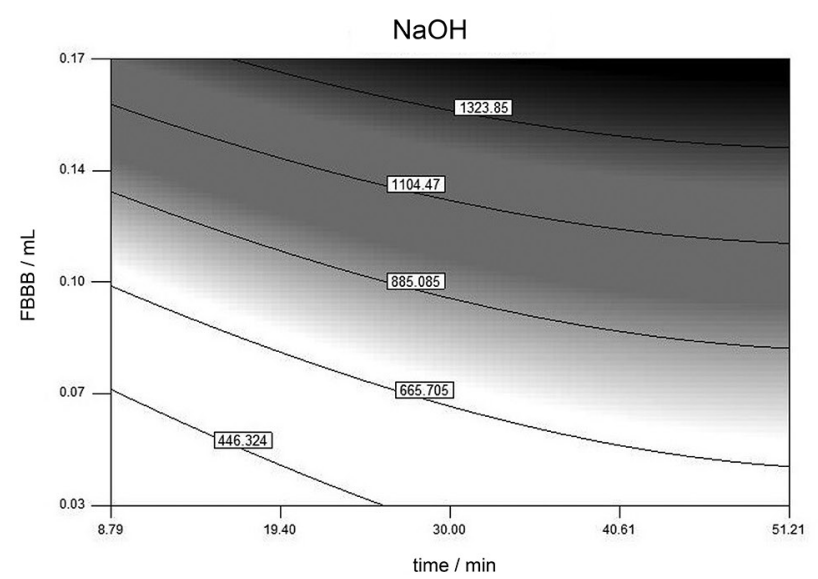

are, the more adjusted the model will be. ${ }^{14}$ As could be observed in Figure 1, the predicted values by the model were closer to the obtained in our experiments.

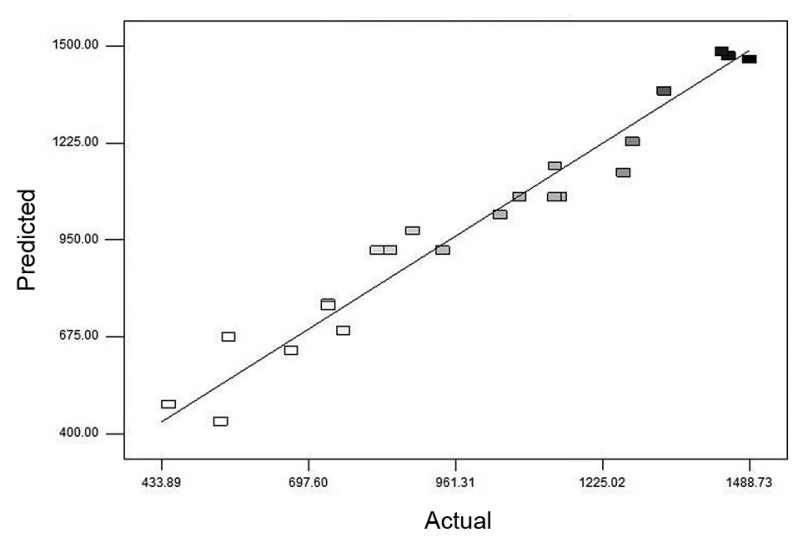

Figure 1. Predicted model values vs. experimental values.

\section{Evaluation of the influence variables}

The model equations shown in Table 2 illustrate the system behavior within the range outlined by the experimental design. For each categorical variable (type of catalyst), there is an equation for the total phenolic content. As previously explained, positive signals indicate synergic effects, while negative signals indicate antagonistic effects. In both equations, the time factor was associated with synergic effects, i.e., increased time resulted in higher responses. This effect was better observed using $20 \% \mathrm{Na}_{2} \mathrm{CO}_{3}$, as the increase in reaction time produces more evident elevation in final results when compared to $5 \% \mathrm{NaOH}$ (Figure 2). A similar effect was observed for FBBB volume, where higher TPC values resulted from larger FBBB volumes added. This response was similar for both catalysts.

All of these results are consistent. A longer reaction time leads to a longer interaction between phenolic compounds

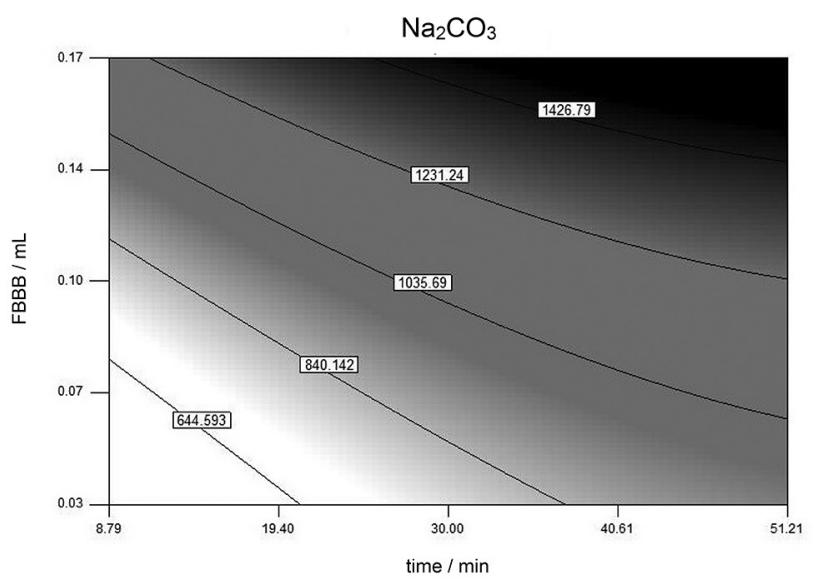

Figure 2. Contour charts showing the effects of Fast Blue $\mathrm{BB}(\mathrm{FBBB})$ reagent volume and time for two catalysts $\left(\mathrm{NaOH}\right.$ and $\left.\mathrm{Na}_{2} \mathrm{CO}_{3}\right)$ on total phenolic values. 
in the rice and the FBBB reagent, yielding better and more reliable results. Moreover, higher volumes of FBBB reagent ensure the reaction with practically every phenolic compound in the sample, which may not occur at lower volumes. These observations suggested FBBB may be the limiting reactant in the process, increasing the risks of underestimation and reducing the confidence level of the final results. This can be predicted by analyzing the system, taking into account the lower and higher limits of the FBBB added (Figure 2). At the lower limit $(0.03 \mathrm{~mL})$, the response increased slightly over time for both catalysts, suggesting a possible limitation to the results due to the low volume of FBBB reagent. However, at the upper limit $(0.17 \mathrm{~mL})$, the results showed a greater variation as a function of time for both catalysts, and the most variable results were obtained from $20 \% \mathrm{Na}_{2} \mathrm{CO}_{3}$.

On the other hand, the interaction between time and FBBB volume leads to a decrease in the final results. However, as this effect was not statistically significant, it was slightly observed in the response surface (Figure 2).

The calibration curve $\mathrm{R}^{2}$ values for each experiment were also evaluated (Table 3 ). The ANOVA values for the linearity were not shown in this work, since the intent to include these data is only to demonstrate how the different variables influence the linearity and not to optimize the system for linearity improvement. The $\mathrm{R}^{2}$ values from calibration curves were added as a principal response of the design, generating, as well as the principal response of the work (TPC), a response surface (Figure 3). These data showed the differences in the linearity values between catalysts more clearly.

When the influence of time on linearity was analyzed, a greater increase in linearity was seen when $5 \% \mathrm{NaOH}$ was used (compared to $20 \% \mathrm{Na}_{2} \mathrm{CO}_{3}$ ). This was in agreement with a previous study carried out by Medina, ${ }^{17}$ where longer reaction times result in higher linearity values. However, as could be observed for both catalysts, at the upper limits of time there was a slight decrease in linearity for the system, which may be due to the decomposition of the product formed by the reaction between gallic acid (used for the calibration curve) and FBBB reagent.

The effect of FBBB volume on linearity was peculiar. Increased volume resulted in a reduction in linearity, while at lower volumes, linearity was improved. This effect was

Table 3. Total phenolic content (TPC) and $\mathrm{R}^{2}$ of experiments

\begin{tabular}{|c|c|c|c|c|c|}
\hline Experiment & $\mathrm{X}_{1}^{\mathrm{a}}$ & $\mathrm{X}_{2}^{\mathrm{b}}$ & $\mathrm{X}_{3}^{\mathrm{c}}$ & TPC / (mg GAE $\left.100 \mathrm{~g}^{-1}\right)$ & $\mathrm{R}^{2}$ \\
\hline E1 & -1 & -1 & $5 \% \mathrm{NaOH}$ & 540.37 & 0.9910 \\
\hline E2 & 1 & -1 & $5 \% \mathrm{NaOH}$ & 759.97 & 0.9980 \\
\hline E3 & -1 & 1 & $5 \% \mathrm{NaOH}$ & 1262.69 & 0.9768 \\
\hline $\mathrm{E} 4$ & 1 & 1 & $5 \% \mathrm{NaOH}$ & 1335.54 & 0.9937 \\
\hline E5 & -1.4142 & 0 & $5 \% \mathrm{NaOH}$ & 555.02 & 0.9032 \\
\hline E6 & 1.4142 & 0 & $5 \% \mathrm{NaOH}$ & 1041.26 & 0.9959 \\
\hline E7 & 0 & -1.4142 & $5 \% \mathrm{NaOH}$ & 447.14 & 0.9919 \\
\hline E8 & 0 & 1.4142 & $5 \% \mathrm{NaOH}$ & 1488.73 & 0.9846 \\
\hline E9 & 0 & 0 & $5 \% \mathrm{NaOH}$ & 821.11 & 0.9873 \\
\hline E10 & 0 & 0 & $5 \% \mathrm{NaOH}$ & 938.41 & 0.9873 \\
\hline E11 & 0 & 0 & $5 \% \mathrm{NaOH}$ & 844.66 & 0.9873 \\
\hline E12 & -1 & -1 & $20 \% \mathrm{Na}_{2} \mathrm{CO}_{3}$ & 666.42 & 0.9672 \\
\hline E13 & 1 & -1 & $20 \% \mathrm{Na}_{2} \mathrm{CO}_{3}$ & 885.05 & 0.9931 \\
\hline E14 & -1 & 1 & $20 \% \mathrm{Na}_{2} \mathrm{CO}_{3}$ & 1139.96 & 0.9253 \\
\hline E15 & 1 & 1 & $20 \% \mathrm{Na}_{2} \mathrm{CO}_{3}$ & 1451.18 & 0.9678 \\
\hline E16 & -1.4142 & 0 & $20 \% \mathrm{Na}_{2} \mathrm{CO}_{3}$ & 732.99 & 0.9290 \\
\hline E17 & 1.4142 & 0 & $20 \% \mathrm{Na}_{2} \mathrm{CO}_{3}$ & 1278.75 & 0.9889 \\
\hline E18 & 0 & -1.4142 & $20 \% \mathrm{Na}_{2} \mathrm{CO}_{3}$ & 733.33 & 0.9949 \\
\hline E19 & 0 & 1.4142 & $20 \% \mathrm{Na}_{2} \mathrm{CO}_{3}$ & 1438.96 & 0.9399 \\
\hline $\mathrm{E} 20$ & 0 & 0 & $20 \% \mathrm{Na}_{2} \mathrm{CO}_{3}$ & 1076.40 & 0.9852 \\
\hline E21 & 0 & 0 & $20 \% \mathrm{Na}_{2} \mathrm{CO}_{3}$ & 1149.20 & 0.9852 \\
\hline $\mathrm{E} 22$ & 0 & 0 & $20 \% \mathrm{Na}_{2} \mathrm{CO}_{3}$ & 1139.32 & 0.9852 \\
\hline
\end{tabular}

${ }^{\mathrm{a}}$ time; ${ }^{\mathrm{b}}$ Fast Blue BB reagent; ${ }^{\mathrm{c}}$ catalyst. 


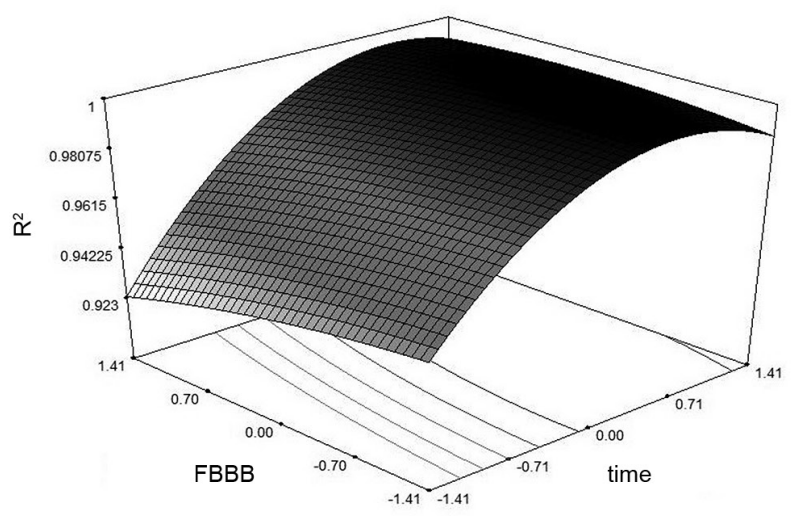

$\mathrm{NaOH}$

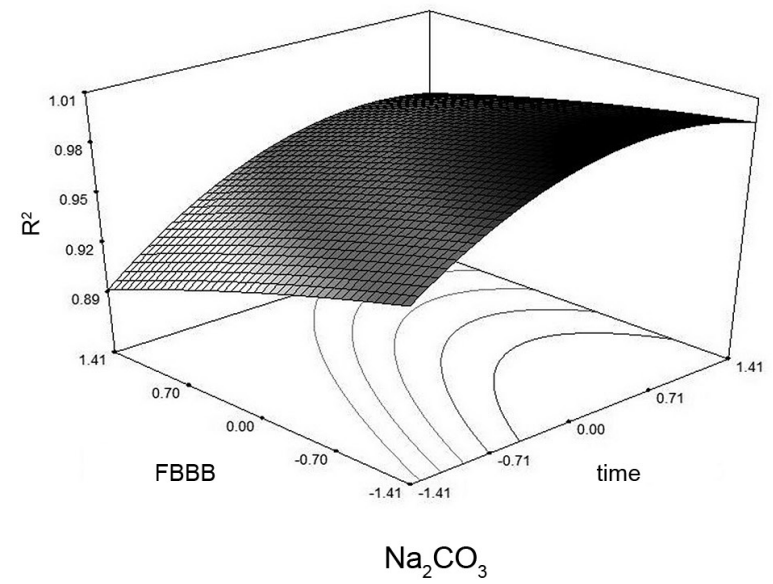

$\mathrm{Na}_{2} \mathrm{CO}_{3}$

Figure 3. Response surface of $\mathrm{R}^{2}$ values for $\mathrm{NaOH}$ and $\mathrm{Na}_{2} \mathrm{CO}_{3}$ catalysts. The units of the variables are in coded format. FBBB: Fast $\mathrm{Blue} \mathrm{BB}$.

more evident when it was used $20 \% \mathrm{Na}_{2} \mathrm{CO}_{3}$ than $5 \% \mathrm{NaOH}$ (Table 3). Taking into account the average reaction time $\left(\mathrm{X}_{1}=0\right.$ or $\left.30 \mathrm{~min}\right)$, the extreme limits of FBBB volume $(-1.4241$ and +1.4142 or 0.03 and $0.17 \mathrm{~mL}$, respectively), and comparing $\mathrm{E} 7$ and $\mathrm{E} 8$ (5\% NaOH catalyst) with $\mathrm{E} 18$ and $\mathrm{E} 19\left(20 \% \mathrm{Na}_{2} \mathrm{CO}_{3}\right.$ catalyst), the difference in the $\mathrm{R}^{2}$ values between E7 and E8 was lower (0.0073) while the difference in $\mathrm{R}^{2}$ values between E18 and E19 was higher (0.055). This difference in $\mathrm{R}^{2}$ values between $\mathrm{NaOH}$ and $\mathrm{Na}_{2} \mathrm{CO}_{3}$ can be explained by the different strength of the catalysts. Both convert the phenolic compounds into phenolate anions, which react quickly. ${ }^{21}$ For this purpose, it is known that the $\mathrm{NaOH}$ is more reactive than $\mathrm{Na}_{2} \mathrm{CO}_{3}$. The strong base reacts well with any FBBB volume (within the range evaluated in this work), which was not the case for $\mathrm{Na}_{2} \mathrm{CO}_{3}$. The reaction of the phenolate anions with FBBB is more ensured when low volumes of reagent are added, leading to better linearity values. However, the increased linearity may not be reliable, because small amounts of FBBB may be limiting reaction. While linearity is improved, the reaction between FBBB and all phenolic compounds present in the sample cannot be assured, leading to underestimation of the final results. Therefore, within the studied range in this work, low volumes of FBBB are not recommended, as it could reduce accuracy of the final results.

\section{Optimization and validation of the model}

TPC results (Table 3) ranged between 447.14 and $1488.73 \mathrm{mg}$ GAE $100 \mathrm{~g}^{-1}$. The models obtained previously (Table 2) predicted slightly higher results than seen experimentally (Figure 2). As the aim was to achieve the optimum condition for the process, the variables were evaluated by the Design Expert software at the maximum intervals $(-1.4142$ to +1.4142$)$ for time and FBBB volume as well as both catalysts, in order to obtain the best possible result. The parameters that described the optimal condition were $38.01 \mathrm{~min}$ reaction time, $0.17 \mathrm{~mL}$ FBBB reagent and $20 \% \mathrm{Na}_{2} \mathrm{CO}_{3}$ (catalyst), with the predicted result of $1550.74 \mathrm{mg}$ GAE $100 \mathrm{~g}^{-1}$. Employing these conditions, 6 replicate experiments yielded an average value of $1461.42 \mathrm{mg} \mathrm{GAE} 100 \mathrm{~g}^{-1}$, which was similar to the predicted value (CV below $8.51 \%$ ), indicating the model predicted the results accurately for the specific conditions.

However, the result of experiment E8 $\left(1488.73 \mathrm{mg} \mathrm{GAE} 100 \mathrm{~g}^{-1}\right)$ for a $30 \mathrm{~min}$ reaction time, $0.17 \mathrm{~mL}$ of FBBB reagent and $5 \% \mathrm{NaOH}$ (catalyst) was similar to that obtained using the optimal condition for the system (Table 3). Thus, we decided to consider this point as the optimal condition of the system. The lower time of the experiment E8 regarding to the proposed by the software (38.01 $\mathrm{min}$ ), which could be a negative point for the final result as discussed above, did not affect the final result, suggesting the difference of $8 \mathrm{~min}$ was not significant. The FBBB volume used in experiment E8 is higher than the proposed in the optimal condition, which avoids potential underestimation of the results. Also, experiment E8 uses the catalyst $(5 \% \mathrm{NaOH})$ obtaining the best linearity values, improving the quality of the final results, which would not be easily achieved with $20 \% \mathrm{Na}_{2} \mathrm{CO}_{3}$. These factors indicate this point as the most adequate to be considered the optimal for the system comparing to the suggested by the software.

It is noteworthy to mention that application of the QUENCHER procedure allows faster evaluation of the TPC of samples, ensuring a faster and more complete interaction between all phenolic compounds in the matrix with the FBBB reagent, avoiding extraction steps and chemical reactions to liberate phenolic compounds for analysis. ${ }^{11}$ This fact is more evident when we compare the values obtained in this work (1488.78 mg GAE $100 \mathrm{~g}^{-1}$ ) with our previous results $\left(30.43 \mathrm{mg} \text { GAE } 100 \mathrm{~g}^{-1}\right)^{22}$ and 
others in literature, such as obtained by Medina ${ }^{17}$ (not detectable), Min et al..$^{23}\left(960 \mathrm{mg}\right.$ GAE $100 \mathrm{~g}^{-1}$ ), Min et al..$^{24}$ (105 mg GAE $100 \mathrm{~g}^{-1}$ ), all of them using extraction steps with different solvents. These steps may be sources of error, as they may not extract/liberate all the phenolic compounds present in the sample, leading to inaccurate quantification, as these extractions/reactions rarely reach $100 \%$ yield. The rapidity of the QUENCHER procedure is evident by observing the reaction time in the optimized condition (30 $\mathrm{min}$ ), which is much lower than the 60 and 90 min reaction time for $\mathrm{NaOH}$ and $\mathrm{Na}_{2} \mathrm{CO}_{3}$, respectively, reported by Medina, ${ }^{17}$ which also employs FBBB for the determination of total phenolic content using solvent extraction.

\section{Conclusions}

Using response surface methodology, it was possible to simultaneously evaluate the influences of all variables studied in this work. This enabled an extensive approach regarding to linearity of the system, showing that not always higher values of linearity are more recommended, as noted in the case of higher values of $\mathrm{R}^{2}$ in low concentrations of FBBB for both catalysts. A great liberty of choice for the optimal point of the system was achieved, which was not limited to the $\mathrm{R}^{2}$ values. Furthermore, the proposed model equation was well adjusted to the results, with good data prediction, indicated by the similarity between predicted and actual values under the optimal condition given by the software. Nevertheless, the optimal point chosen for the system, taking into account the similarity of the obtained results in a shorter reaction time, was based on the E8 experiment conditions, which used a 30 min reaction time, $0.17 \mathrm{~mL}$ FBBB reagent and $5 \% \mathrm{NaOH}$ as catalyst. Thus, the use of a specific reagent (FBBB) along with the employment of the direct QUENCHER procedure, which was used together for the first time in TPC determination, proved to be faster and more efficient/accurate when compared to other procedures using FBBB reagent, and it could also be applied in the study of other food matrices.

\section{Acknowledgments}

This work was supported by Coordenação de Aperfeiçoamento de Pessoal de Nível Superior (CAPES).

\section{References}

1. Liu, R. H.; J. Cereal Sci. 2007, 46, 207.
2. Tananuwong, K.; Tewaruth, W.; LWT--Food Sci. Technol. 2010, $43,476$.

3. Tufan, A. N.; Çelik, S. E.; Özyürek, M.; Güçlü, K.; Apak, R.; Talanta 2013, 108, 136.

4. Klaunig, J. E.; Wang, Z.; Pu, X.; Zhou, S.; Toxicol. Appl. Pharmacol. 2011, 254, 86.

5. Folin, O.; Ciocalteu, V.; J. Biol. Chem. 1927, 73, 627.

6. Singleton, V. L.; Rossi, J. A.; Am. J. Enol. Vitic. 1965, 16, 144.

7. Sánchez-Rangel, J. C.; Benavides, J.; Heredia, J. B.; CisnerosZevallos, L.; Jacobo-Velázquez, D. A.; Anal. Methods 2013, 5, 5990.

8. Prior, R. L.; Wu, X.; Schaich, K.; J. Agric. Food Chem. 2005, 53, 4290 .

9. Medina, M. B.; J. Funct. Foods 2011, 3, 79.

10. Lester, G. E.; Lewers, K. S.; Medina, M. B.; Saftner, R. A.; J. Food Compos. Anal. 2012, 27, 102.

11. Serpen, A.; Gökmen, V.; Pellegrini, N.; Fogliano, V.; J. Cereal Sci. 2008, 48, 816.

12. Gökmen, V.; Serpen, A.; Fogliano, V.; Trends Food Sci. Technol. 2009, 20, 278.

13. Silva, E. M.; Rogez, H.; Larondelle, Y.; Sep. Purif. Technol. 2007, 55, 381.

14. Neto, B. B.; Scarminio, I. S.; Bruns, R. E.; Como Fazer Experimentos: Pesquisa e Desenvolvimento na Ciência e na Indústria, $3^{\mathrm{a}}$ ed.; UNICAMP: Campinas, 2007.

15. Sellapan, K.; Datta, K.; Parkhi, S. K.; Datta, S. K.; Plant Sci. (Shannon, Irel.) 2009, 177, 557.

16. http://faostat.fao.org/site/339/default.aspx accessed in December 2015.

17. Medina, M. B.; J. Agric. Food. Chem. 2011, 59, 1565.

18. Stat-Ease, Inc.; Design Expert Software version 7.1; Minneapolis, USA, 2008.

19. Barizão, É. O.; Martins, A. C.; Ercoli, L.; Kvitschal, M. V.; Silva, R.; Junior, O. P.; Visentainer, J. V.; Almeida, V. C.; Food Anal. Methods 2013, 6, 1407.

20. Santos, O. O.; Maruyama, S. A.; Claus, T.; Souza, N. E.; Matsushita, M.; Visentainer, J. V.; Fuel 2013, 113, 580.

21. Solomons, T. W. G.; Fryhle, C. B.; Organic Chemistry, $7^{\text {th }}$ ed.; John Wiley \& Sons, New Jersey, 2000.

22. Palombini, S. V.; Maruyama, S. A.; Claus, T.; Carbonera, F.; Souza, N. E.; Visentainer, J. V.; Gomes, S. T. G.; Matsushita, M.; Food Sci. Technol. 2013, 33, 699.

23. Min, B.; McClung, A. M.; Chen, M. H.; J. Food Sci. 2011, 76, C117.

24. Min, B.; Gu, L.; McClung, A. M.; Bergman, C. J.; Chen, M. H.; Food Chem. 2012, 133, 715.

Submitted: October 1, 2015

Published online: January 21, 2016 